\title{
Nanostructure and Bonding of Zirconium Diboride Thin Films Studied by X-ray Spectroscopy
}

\author{
David M. Stewart, Robert W. Meulenberg, Robert J. Lad \\ Department of Physics $\mathcal{E}$ Astronomy, and Laboratory for Surface Science $\mathcal{E}$ Technology, \\ University of Maine, Orono, ME, 04469
}

\begin{abstract}
Zirconium diboride $\left(\mathrm{ZrB}_{2}\right)$ is an important ceramic due to its extremely high melting temperature of $3245^{\circ} \mathrm{C}$ and metallic electrical conductivity, properties that make it an ideal candidate thin film electrode material for high temperature electronics. In this report, thin films of varying $\underline{B}: \mathrm{Zr}$ ratio ranging from 3-0.67 have been grown by e-beam evaporation from elemental sources. X-ray absorption spectra at the $\mathrm{Zr} \mathrm{K}$-edge were measured before and after annealing in ultra-high vacuum for 9 hours at $1000^{\circ} \mathrm{C}$. Films with compositions near $\mathrm{ZrB}_{2}$ stoichiometry show $\mathrm{x}$-ray absorption fine structure that can be well modeled by crystalline $\mathrm{ZrB}_{2}$ with a small portion of a coexisting tetragonal zirconia $\left(\mathrm{t}-\mathrm{ZrO}_{2}\right)$ phase. Films far from stoichiometry show substantial disorder beyond the nearest-neighbor distances, and after vacuum annealing exhibit high levels of oxidation. Contributions to the $\mathrm{x}$-ray absorption fine structure from a pure $\mathrm{Zr}$ phase are very small compared to $\mathrm{ZrB}_{2}$ and $\mathrm{t}-\mathrm{ZrO}_{2}$ phases. The fact that nearly stoichiometric $(\underline{3<\mathrm{B}: \mathrm{Zr}<1.6)}$ as-deposited amorphous films form the same crystalline $\mathrm{ZrB}_{2}$ nanostructure after annealing is particularly encouraging for high temperature thin film electronics applications, because it would allow the production of highly stable electrodes with e-beam evaporation without the need of any high temperature heating during film growth.
\end{abstract}

Keywords: zirconium diboride, thin film, high temperature, XANES, EXAFS, nanostructure

Email address: david.stewart@maine.edu (David M. Stewart) 


\section{Introduction}

In the last decade, considerable effort has been directed at studying compounds of bulk zirconium diboride $\left(\mathrm{ZrB}_{2}\right)$ for structural aerospace applications,[1-4] owing to the extremely high melting temperature $\left(3245^{\circ} \mathrm{C}\right)$ and large energy barriers for defect formation. $[5,6] \mathrm{ZrB}_{2}$, like other transition metal borides, is also an excellent electrical conductor, exhibiting metallic-like conductivity that is higher than in nitride and carbide materials.[5, 7] Combined with remarkable high temperature stability, these properties make $\mathrm{ZrB}_{2}$ an attractive material for thin film based electronic devices that must withstand harsh, high temperature environments. [7, 8]

For several decades is has been known that agglomeration limits the morphological stability of 
films were characterized before and after annealing up to $1000^{\circ} \mathrm{C}$ in ultra-high vacuum (UHV). However, many films were amorphous and were largely unaffected by annealing for only 1 hour, thus characterization of the film structure was difficult. In this paper, the x-ray absorption near edge spectra (XANES) and extended x-ray absorption fine structure (EXAFS) are reported for ZrB films that are amorphous as deposited, as well as films with excess $\mathrm{Zr}$ content. X-ray absorption spectroscopy permits the investigation of both crystalline and amorphous phases in these films before and after much longer vacuum annealing times (9 hours) at $1000^{\circ} \mathrm{C}$.

\section{Experimental}

\subsection{Film Growth and Characterization}

Thin films with different Zr-B compositions were grown using e-beam co-evaporation from elemental Zr and B sources (99.5\% purity), as described previously.[22] As before, film composition was measured using x-ray photoelectron spectroscopy (XPS) analysis of the newly grown film surface before exposure to air. In this study, films grown with $\mathrm{B}: \mathrm{Zr}$ ratios measured to be $3,1.6$, and $\underline{0.67}$ were selected, covering a range from B-rich $\mathrm{ZrB}_{2}$ to about half way between $\mathrm{ZrB}_{2}$ and pure Zr. The XPS results showed low levels of contamination in the films, with 5-10 at\% C (increasing at higher B:Zr ratios) and typically 3-14 at\% O (increasing at lower B:Zr ratios.)

Films were deposited onto polished r-cut sapphire substrates, either at ambient temperature or while the substrate was heated to $600^{\circ} \mathrm{C}$, in a UHV chamber with base pressure $<10^{-7} \mathrm{~Pa}$. The rate of film growth was limited by a minimum measurable B evaporation rate of $0.1 \AA / \mathrm{s}$, which forced the total growth rate to vary between $0.37 \AA$ /s for films near $\mathrm{ZrB}_{2}$ stoichiometry up to $0.64 \AA$ / $/ \mathrm{s}$ for films at a B:Zr ratio of 0.67 . Following deposition, films were annealed in vacuum $\left(<10^{-4} \mathrm{~Pa}\right)$ at $1000^{\circ} \mathrm{C}$ for a cumulative 9 hours. During annealing, outgassing primarily released $\mathrm{H}_{2} \mathrm{O}, \mathrm{CO}$, and $\mathrm{CO}_{2}$ into the chamber, as determined by a residual gas analyzer. After 1 hour at $1000^{\circ} \mathrm{C}$, films were removed from vacuum and examined for grain growth with x-ray diffraction (XRD), then reinserted for a further 8 hours of annealing, after which XRD was performed again. For XRD measurements $\underline{\text { a Bragg-Brentano geometry was used with a } 7^{\circ} \text { sample tilt to remove diffraction from the sapphire }}$ substrates.

X-ray absorption spectra (XAS) at the Zr K-edge were recorded using florescence measurements at the MRCAT beamline 10-BM at Argonne National Laboratory.[23] Magic angle spinning at grazing incidence was employed to remove strong Bragg diffraction of the beam from the sap- 
phire substrate and minimize the effects of crystallographic texture in the films themselves. The sample area was $8 \mathrm{~mm} \times 8 \mathrm{~mm}$, with a film thickness of $\sim 200 \mathrm{~nm}$, and a beam spot size of $0.5 \mathrm{~mm}$ $\times 20 \mathrm{~mm} . \mathrm{A} \mathrm{ZrB}_{2}$ powder standard (99.5\% purity, 44 micron particle size, tape mounted) was also scanned in transmission mode. A pair of $\mathrm{Si}(111)$ monochromators were used, and initial energy calibration was performed with a $\mathrm{Zr}$ foil in the incident beam (after $\mathrm{I}_{0}$ ). Thereafter, $\mathrm{Zr}$ reference foils were kept after the sample in the transmitted beam (after $\left.\mathrm{I}_{t}\right)$ for scan-to-scan energy alignment.

\subsection{XAS Data Analysis}

XAS data processing was performed using the Demeter software package.[24] The absorption edge was determined by the first and second derivative, and the spectra were background subtracted by fitting pre-edge and post-edge polynomials and normalized by the difference between these polynomials at the absorption edge. The EXAFS was isolated by fitting a smooth, cubic spline polynomial above the edge and subtracting it from the data. This spline was fit up to $k=15 \AA^{-1}$ where possible, but in two cases aberrant oscillations prevented fitting beyond $k=12 \AA^{-1}$. The EXAFS were then weighted by $k^{2}$ and Fourier transformed from $2-12 \AA^{-1}$.

The EXAFS data were modeled using several single scattering paths (and one double scattering path) from crystalline $\mathrm{ZrB}_{2}$ and tetragonal zirconia $\left(\mathrm{t}-\mathrm{ZrO}_{2}\right)$ structures, and fit over a range of 1.154.7 Ån $R$. An example spectrum and fit of a film at a B:Zr ratio of 3 after annealing is shown in Fig. 1, with corresponding fitting parameters shown in Table 1. This model constrains all paths to the same amplitude reduction factor and offset in the absorption edge position. Three DebyeWaller factors $(\sigma)$ were used: one for the first $\mathrm{O}$ and B shells, a second for the first and second $\mathrm{Zr}$ shells, and a third for the third $\mathrm{Zr}$ shell and the double scattering path. Because of the high symmetry of the $\mathrm{ZrB}_{2}$ lattice, the half-path lengths for those paths were fitted with two hexagonal lattice parameters, $a$ and $c$, while a single fitted parameter was subtracted from the two $\mathrm{t}-\mathrm{ZrO} \mathrm{r}_{2}$ paths. Finally, a parameter approximately representing the percentage composition of each phase in the film was multiplied by the amplitude.

\section{Results \& Discussion}

XRD analysis (not shown) indicated that, for all compositions, films deposited with no substrate heating were amorphous, while films deposited with heating showed a fine degree of nanograined structure and preferred crystallographic texture. Films with $\mathrm{B}: \mathrm{Zr}>2$ were preferentially oriented in the $\langle 10 \overline{1} 0\rangle$ direction, though other orientations were found as well. Films with $\mathrm{B}: \mathrm{Zr}<2$ were 
oriented in the $\langle 0001\rangle$ direction. Specifically, one B-rich film deposited at $600^{\circ} \mathrm{C}(\underline{\mathrm{B}: \mathrm{Zr} \text { ratio 3}}$, denoted as film 1 in subsequent discussion), exhibited exceptionally strong $\mathrm{ZrB}_{2}$ (0001) peak crystallinity, that remained unchanged after annealing at $1000^{\circ} \mathrm{C}$ for 9 hours. In Zr-rich films deposited with heating, XRD patterns revealed the growth of $\mathrm{ZrB}_{2}$ crystallites, as well as the formation of sparse, randomly oriented $\mathrm{t}-\mathrm{ZrO}_{2}$ grains after annealing. However, in films deposited at ambient temperature and subsequently annealed, both $\mathrm{ZrB}_{2}$ and $\mathrm{t}-\mathrm{ZrO}_{2}$ grain growth was suppressed. The formation of $\mathrm{t}-\mathrm{ZrO}_{2}$ (instead of monoclinic $\mathrm{ZrO}_{2}$ ) is consistent with other reports of preferential growth of the tetragonal phase due to confinement during oxidation of nanolaminate films,[14, 25, 26] and may be induced by compressive stresses during oxidation of $\mathrm{ZrB}_{2} .[27]$

\subsection{XANES of Zr-B Thin Films}

Fig. 2 shows the XANES from Zr-B films with B:Zr ratios of 3,1.6, and 0.67, as deposited and after annealing at $1000^{\circ} \mathrm{C}$ for 9 hours in vacuum. The first derivatives of these spectra are provided as an aid for the reader, to better illustrate the shifts in edge position and shape. XANES from a $\mathrm{Zr}$ foil standard and a $\mathrm{ZrB}_{2}$ powder reference are also displayed in Fig. 2 for comparison. The data are offset for clarity, beginning with B-rich films at the bottom, and moving upward with increasing $\mathrm{Zr}$ concentration. The $\mathrm{Zr}$ K-edge energy for $\mathrm{ZrB}_{2}$ is found to be shifted up by $1 \mathrm{eV}$ relative to the $\mathrm{Zr}$ foil, and the $\mathrm{Zr}$ foil exhibits a two step edge characteristic of elemental $\mathrm{Zr}$,[28] which is not present in the $\mathrm{ZrB}_{2}$ powder.

Three trends emerge from the data in Fig. 2a. The first is a smooth decrease in the edge energy with increasing $\mathrm{Zr}$ concentration for as-deposited films. As the $\mathrm{B}: \mathrm{Zr}$ ratio reaches 0.67 , the edge energy becomes aligned with that of the $\mathrm{Zr}$ foil. The second trend is the increased prominence of a pre-edge feature as the $\mathrm{Zr}$ concentration increases. This feature is associated with transitions into hybridized p-d states in elemental $\mathrm{Zr}$.[28, 29] Since there is no hybridization of the $\mathrm{Zr} \mathrm{p}$ and $\mathrm{d}$ states in $\mathrm{ZrB}_{2}$,[30] this feature is suppressed at compositions around $\mathrm{ZrB}_{2}$ stoichiometry. Finally, the features above the edge change from a large dip in absorption seen in the $\mathrm{ZrB}_{2}$ standard, to a more level absorption plateau with two peaks near the edge as seen in the $\mathrm{Zr}$ foil.

After vacuum annealing at $1000^{\circ} \mathrm{C}$ (Fig. 2b), these trends with composition are no longer present. Prior to annealing, films 3 and 4 show less $\mathrm{ZrB}_{2}$ character in their XANES than films 1 and 2, but after annealing all four films exhibit almost identical XANES features. Film 1 (B:Zr $\underline{\text { ratio } 3}$, deposited with heating) was unchanged by annealing, which agrees with XRD results that indicate a much higher degree of $\mathrm{ZrB}_{2}$ crystallinity. The edge energy of all films is shifted higher 


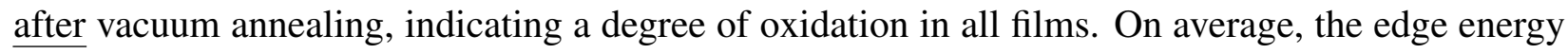
of films 1-4 shifted up to $3.6 \mathrm{eV}$ above that of the $\mathrm{Zr}$ standard.

Films 5 and 6 (B:Zr ratio 0.67, deposited with and without substrate heating, respectively), which originally had similar features to the $\mathrm{Zr}$ foil, lack the pre-edge step after annealing, as well as the post-edge plateau and pair of peaks. The K-edge energy is shifted upwards to $4.1 \mathrm{eV}$ above the $\mathrm{Zr}$ foil (an energy which is consistent with a large amount of $\mathrm{ZrO}_{2}$ phase) despite receiving the same level of exposure to atmosphere after deposition as the other films.

The XPS from films 5 and 6 exhibited a second, chemically shifted $\mathrm{ZrO}_{2}$ doublet between the $\underline{\text { B } 1 \mathrm{~s} \text { and } \mathrm{Zr} \mathrm{3d_{3/2 }} \text { peaks. This region was fit with Doniach-Sunjic-like line shapes for the B } 1 \mathrm{~s} \text { and }}$ Zr 3d doublet against a Tougaard-like background, with two additional Voigt-like line shapes for the $\mathrm{ZrO}_{2}$ doublet.[22] As seen in Fig. 2a, this disordered oxide phase had little effect on the overall electronic structure of the films based on the as-deposited XANES. After annealing the upward shift in edge energy and changes in the pre- and post-edge features in the XANES of films 5 and 6 imply significant rearrangment of the oxide phase, the coexistence of $\mathrm{ZrB}_{2}$ and oxide phases, and the absence of any elemental Zr phase.

\subsection{EXAFS of Near-Stoichiometric Films}

The model used to fit the data (described in Sec. 2.2) is based on the structural information deduced from the XRD data. No crystalline phases other than $\mathrm{ZrB}_{2}$ and $\mathrm{t}-\mathrm{ZrO}_{2}$ were observed in these $\mathrm{Zr}-\mathrm{B}$ thin films. Therefore, the model assumes that the EXAFS is a linear combination of scattering paths from these two phases. A fitting parameter corresponding to the fraction of $\mathrm{ZrB}_{2}$ phase, balanced by a $\mathrm{t}-\mathrm{ZrO}_{2}$ phase, was included as a multiplicative factor on the amplitude of the paths. Films 1-4 were all fitted in this way, and the correlations between the $\mathrm{ZrB}_{2}$ fraction and the amplitude was found to be less than 0.4 in each fit. The $\mathrm{ZrB}_{2}$ fraction varied from 0.97 to 0.83 between films, with an average uncertainty of 0.051 in each fit. Thus, these four films contained nearly the same composition of $\mathrm{ZrB}_{2}$ and $\mathrm{t}-\mathrm{ZrO}_{2}$ phases after annealing.

Figs. $3 \mathrm{a}$ and $\mathrm{b}$ show the magnitude of the Fourier transform of the EXAFS data for films 1-4 before annealing. Films deposited with substrate heating (1 and 3) show much longer range order than films deposited at ambient temperature ( 2 and 4), with visible peaks out to almost $4.5 \AA$. Films 2 and 4 show only a small degree of nearest-neighbor order. The broad peak around $2 \AA$ corresponds to first shell $\mathrm{B}$ and $\mathrm{O}$ atoms, which have very similar bond lengths, as seen in Fig. 1. Peaks at $3 \AA$ and $4.3 \AA$ correspond to the first three Zr shells in the system, and the absence of these 
peaks in films 2 and 4 implies very low order in the $\mathrm{Zr}-\mathrm{Zr}$ bond distances at low film deposition temperature. This is not surprising for amorphous films, however, and can be explained by a lower rate of atomic diffusion during deposition.

Surprisingly, after annealing at $1000^{\circ} \mathrm{C}$ for 9 hours, all four films have very similar EXAFS features. Figs. $3 \mathrm{c}$ and d show the magnitude of the Fourier transform of the films after annealing, as well as the best fit of the data to the two phase $\left(\mathrm{ZrB}_{2}\right.$ and $\left.\mathrm{t}-\mathrm{ZrO}_{2}\right)$ model. Generally, the fits are quite good, though in all four samples there is intensity in the B peak that is unaccounted for, and the shoulder produced by the $\mathrm{O}$ path is greater than the data. Since the path degeneracy (interpreted as the coordination number in single scattering paths) was not varied from that of pure $\mathrm{ZrB}_{2}$ and $\mathrm{t}-\mathrm{ZrO}_{2}$ phases, this disagreement with the model may indicate that, on average, there are fewer than eight $\mathrm{O}$ nearest-neighbors at each $\mathrm{Zr}$ site. Additionally, the deviation of B intensity from that of crystalline $\mathrm{ZrB}_{2}$ implies the coexistance of $\mathrm{B}$ and $\mathrm{Zr}$ within the unordered, amorphous phase in the films, which has only short-range order.

Values for the $\mathrm{Zr}-\mathrm{B}$ bond length and $\mathrm{ZrB} 2$ lattice parameters derived from these fits are presented in Table 2 for films 2 and 4, as well as for the $\mathrm{ZrB}_{2}$ powder standard and results reported for bulk $\mathrm{ZrB}_{2}$.[31] There is good agreement between the values in Ref. [31] and the data here for the $\mathrm{ZrB}_{2}$ powder, and the $\mathrm{Zr}-\mathrm{B}$ bond lengths for all four measurements are in agreement as well. The $a$ and $c$ lattice parameters are generally not in agreement, however. The B-rich films have a longer $a$ axis than in bulk, but the $c$ axis is similar. Just above $\mathrm{ZrB}_{2}$ stoichiometry, the $a$ axis is longer still, and the $c$ axis is below the bulk values by more than twice the uncertainty in the fitted parameter. Zr-rich films were found by XRD to be preferentially oriented in the $\langle 10 \overline{1} 0\rangle$ direction, so compression of the $c$ axis is not unreasonable.

\subsection{EXAFS of Films Far from $\mathrm{ZrB}_{2}$}

Fig. 4a shows the EXAFS from as-deposited Zr-rich films (B:Zr ratio 0.67). Both films exhibit weaker EXAFS signals than films 1-4, indicating a higher degree of disorder even in the nearest neighbor regions. Film 5 (deposited with substrate heating) shows a small peak just below $3 \AA$, corresponding to scattering from $\mathrm{Zr}$ sites. This peak appears at smaller lengths than in films near $\mathrm{ZrB}_{2}$ stoichiometry, which is consistent with increased scattering from nearest neighbor $\mathrm{Zr}$ sites in elemental Zr. Both films 5 and 6 also exhibit broad peaks between 1-2.5 $\AA$, similar to those seen in nearly stoichiometric films.

Fig. $4 \mathrm{~b}$ shows the results of vacuum annealing films 5 and 6 at $1000^{\circ} \mathrm{C}$. The EXAFS signal 
from these films did strengthen after annealing, but not as much as for the nearly stoichiometric films. It is clear from the strong peaks at $1.5 \AA$, corresponding to $\mathrm{O}$ scattering, that the level of oxidation is much greater in films 5 and 6 compared to nearly stoichiometric films, and that film 5 is more oxidized than film 6. There is also an observed splitting in the $\mathrm{Zr}$ scattering peak in film 5, due to the scattering from first shell $\mathrm{Zr}$ in the $\mathrm{t}-\mathrm{ZrO}_{2}$ phase. The EXAFS of film 6 shows a smaller shoulder on the high side of the $\mathrm{Zr}$ scattering peak, due to a smaller amount of $\mathrm{t}-\mathrm{ZrO}_{2}$ phase, which is consistent with the XANES analysis from Sec. 3.1.

When attempting to apply the two phase model previously discussed to the data in Fig. 4, it was found that the fit considerably underestimated the intensity at the lower edge of the $\mathrm{Zr}$ scattering peak. The nearest neighbor $\mathrm{Zr}$ scattering path in elemental $\mathrm{Zr}$ provides strong intensity at the lower edge of the $3 \AA$ peak. Thus, the fitting model was modified to include contributions from elemental $\mathrm{Zr}$ paths, as shown in Fig. $4 \mathrm{c}$, and used to fit the data in Fig. $4 \mathrm{~b}$. Due to the number of paths that contribute to the same region, the $a$ and $c$ axis lengths for the $\mathrm{ZrB}_{2}$ paths were constrained to the average values found in fitting the near-stoichiometric films, leaving the elemental $\mathrm{Zr}$ and $\mathrm{t}-\mathrm{ZrO}_{2}$ path lengths to vary independently. An additional parameter representing the fraction of elemental $\mathrm{Zr}$ was used to allow the modeling of a three phase mixture, but the values for these parameters can only be discussed qualitatively due to increased correlations with other parameters in the fit.

Fitting the data from films 5 and 6 indicates that the intensity contributions from an elemental $\mathrm{Zr}$ phase were less than a quarter of the contributions from $\mathrm{ZrB}_{2}$ and $\mathrm{t}-\mathrm{ZrO}_{2}$ phases. In fact, overwhelmingly the strongest peaks in the Fourier transform are from the $\mathrm{t}-\mathrm{ZrO}_{2}$ paths. $\mathrm{XRD}$ spectra from these films showed only diffraction from these same two phases, with no evidence of a pure $\mathrm{Zr}$ crystalline phase. The lack of XRD peaks from a metallic Zr phase could be due to the fact that the majority of highly reactive $\mathrm{Zr}$ atoms not already in a $\mathrm{ZrB}_{2}$-like environment become preferentially oxidized and form the $\mathrm{t}-\mathrm{ZrO}_{2}$ phase seen in the EXAFS. Furthermore, it was estimated from XPS that, as deposited, around than $40 \%$ of the $\mathrm{Zr}$ atoms in films 5 and 6 were in an oxide phase, and $\underline{\text { so despite the } 24000 \text { Langmuirs of exposure to background gases during vacuum annealing, very }}$ little additional oxidation of the zirconium was actually observed.

\section{Conclusions}

The fabrication of highly stoichiometric $\mathrm{ZrB}_{2}$ thin films is an important step in the development of high temperature thin film electronics. Thin films with different $\mathrm{Zr}$-B compositions were grown 

Segre for their assistance and valuable discussion. MRCAT operations are supported by the Department of Energy and the MRCAT member institutions. This research used resources of the Advanced Photon Source, a U.S. Department of Energy (DOE) Office of Science User Facility 

AC02-06CH11357. 
[1] M. M. Opeka, I. G. Talmy, and J. A. Zaykoski, J. Mater. Sci. 39, 5887 (2004).

[2] V. O. Lavrenko, A. D. Panasyuk, O. M. Grigorev, O. V. Koroteev, and V. A. Kotenko, Powder Metall. Met. Ceram. 51, 217 (2012).

[3] Y.-H. Seong and D. K. Kim, Ceram. Int. 40, 15303 (2014).

[4] L. Silvestroni, G. Meriggi, and D. Sciti, Corros. Sci. 83, 281 (2014).

[5] W. G. Fahrenholtz, G. E. Hilmas, I. G. Talmy, and J. a. Zaykoski, J. Am. Ceram. Soc. 90, 1347 (2007).

[6] S. C. Middleburgh, D. C. Parfitt, P. R. Blair, and R. W. Grimes, J. Am. Ceram. Soc. 94, 2225 (2011).

[7] W. S. Williams, "Transition metal carbides, nitrides, and borides for electronic applications," (1997).

[8] J. Shappirio, J. Finnegan, R. Lux, D. Fox, and J. Kwiatkowski, J. Vac. Sci. Technol. A 3, 2255 (1985).

[9] W. Maskell, J. Phys. D. Appl. Phys. 20, 99 (1987).

[10] E. Jiran and C. V. Thompson, Thin Solid Films 208, 23 (1992).

[11] C. V. Thompson, Annu. Rev. Mater. Res. 42, 399 (2012).

[12] S. C. Moulzolf, D. J. Frankel, M. Pereira da Cunha, and R. J. Lad, Microsyst. Technol. 20, $523(2013)$.

[13] E. Çiftyürek, K. Sabolsky, and E. M. Sabolsky, Sensors Actuators B Chem. 181, 702 (2013).

[14] J. C. Sell, D. M. Stewart, G. P. Bernhardt, D. J. Frankel, and R. J. Lad, J. Vac. Sci. Technol. B 33, 021805 (2015).

[15] H. Chen, F. Zheng, H. Liu, L. Liu, and Z. Jin, J. Alloys Compd. 468, 209 (2009).

[16] H. Nowotny, E. Rudy, and F. Benesovsky, Monatshefte für Chemie und verwandte Teile anderer Wissenschaften 91, 963 (1960). 
[17] Y. Champion and S. Hagge, J. Mat. Sci. Lett. 11, 290 (1992).

[18] J. Li and C. Fan, Phys. Chem. Chem. Phys. 17, 1180 (2015).

[19] M. Samuelsson, J. Jensen, U. Helmersson, L. Hultman, and H. Högberg, Thin Solid Films 526, 163 (2012).

[20] D. Lee, G.-D. Sim, K. Xiao, and J. J. Vlassak, J. Phys. Chem. C 118, 21192 (2014).

[21] L. Tengdelius, M. Samuelsson, J. Jensen, J. Lu, L. Hultman, U. Forsberg, E. Janzén, and H. Högberg, Thin Solid Films 550, 285 (2014).

[22] D. M. Stewart, D. J. Frankel, and R. J. Lad, J. Vac. Sci. Technol. A 33 (2015), $10.1116 / 1.4916565$.

[23] A. J. Kropf, J. Katsoudas, S. Chattopadhyay, T. Shibata, E. A. Lang, V. N. Zyryanov, B. Ravel, K. McIvor, K. M. Kemner, K. G. Scheckel, S. R. Bare, J. Terry, S. D. Kelly, B. A. Bunker, and C. U. Segre, in AIP Conf. Proc., Vol. 1234 (2010) pp. 299-302.

[24] B. Ravel and M. Newville, J. Synchrotron Radiat. 12, 537 (2005).

[25] C. Scanlan, M. Gajdardziska-Josifovska, and C. Aita, Applied Physics Letters 64 (1994).

[26] C. Aita, M. Wiggins, R. Whig, C. Scanlan, and M. Gajdardziska-Josifovska, Journal of Applied Physics 79 (1996).

[27] Z. Zhou, X. Peng, and Z. Wei, J. Am. Ceram. Soc. 98, 629 (2015).

[28] M. Gupta and A. Nigam, J. Phys. F Met. Phys. 4, 947 (1974).

[29] T. Yamamoto, X-Ray Spectrom. 37, 572 (2008).

[30] X. Zhang, X. Luo, J. Han, J. Li, and W. Han, Comput. Mater. Sci. 44, 411 (2008).

[31] W. Chu, Z. Wu, W. Liu, N. Saini, A. Bianconi, T. Hu, and Y. Xie, Radiat. Phys. Chem. 75, 2080 (2006). 
Table 1: Table of fitting parameters used in modeling the EXAFS spectra in Fig. 1. The $\mathrm{ZrB}_{2}$ paths were constrained to the hexagonal lattice parameters $a$ and $c$, while the $\mathrm{t}-\mathrm{ZrO}_{2}$ paths were fitted with a constant offset.

\begin{tabular}{lcll}
\hline & \multicolumn{4}{c}{ Half-Path Length } \\
Path & Function & Value $(\AA)$ & $\sigma\left(\times 10^{-3}\right)$ \\
\hline $\mathrm{B}_{1}$ & $\sqrt{\frac{a^{2}}{3}+\frac{c^{2}}{4}}$ & 2.546 & $3.99(1.80)$ \\
$\mathrm{Zr}_{1}$ & $a$ & $3.182(8)$ & $3.35(1.00)$ \\
$\mathrm{Zr}_{2}$ & $c$ & $3.526(15)$ & $3.35(1.00)$ \\
$\mathrm{Zr}_{3}$ & $\sqrt{a^{2}+c^{2}}$ & 4.749 & $4.26(1.11)$ \\
$\mathrm{B}_{1}-\mathrm{Zr}_{3}$ & $\mathrm{~B}_{1}+\frac{1}{2} \mathrm{Zr}_{3}$ & 4.921 & 5.84 \\
\hline $\mathrm{O}_{1}$ & $0.2220-\Delta$ & $2.207(39)$ & $3.99(1.80)$ \\
$\mathrm{Zr}_{1}$ & $0.3625-\Delta$ & $3.612(39)$ & $3.35(1.00)$ \\
\hline
\end{tabular}


Table 2: Fitted values for the $\mathrm{ZrB}_{2}$ lattice parameters and $\mathrm{Zr}-\mathrm{B}$ bond distance in films 2 and 4 after annealing, compared with the $\mathrm{ZrB}_{2}$ powder standard, and Ref. [31].

\begin{tabular}{llll}
\hline Sample & Distance & Value $(\AA)$ & $\sigma\left(\times 10^{-3}\right)$ \\
\hline Ref [31] & $\mathrm{Zr}-\mathrm{B}$ & $2.54(6)$ & $4.2(6)$ \\
& $a$ & $3.18(0)$ & $2.6(5)$ \\
& $c$ & $3.54(2)$ & $2.9(8)$ \\
$\mathrm{ZrB}_{2}$ & $\mathrm{Zr}-\mathrm{B}$ & 2.542 & $4.62(1.86)$ \\
powder & $a$ & $3.175(5)$ & $2.60(97)$ \\
& $c$ & $3.532(20)$ & $2.60(97)$ \\
Film 2 & $\mathrm{Zr}-\mathrm{B}$ & 2.550 & $4.17(1.56)$ \\
& $a$ & $3.192(7)$ & $3.73(81)$ \\
& $c$ & $3.527(13)$ & $3.73(81)$ \\
Film 4 & $\mathrm{Zr}-\mathrm{B}$ & 2.549 & $6.15(2.17)$ \\
& $a$ & $3.208(8)$ & $4.20(88)$ \\
& $c$ & $3.504(13)$ & $4.20(88)$ \\
\hline
\end{tabular}




\section{List of Figures}

1 (Color online) Example plot of the magnitude of the EXAFS Fourier transform of a Zr-B film (B:Zr ratio of 3), with the fit using the parameters shown in Table 1. Offset for clarity are the magnitudes of the component paths from the $\mathrm{ZrB}_{2}$ and $\mathrm{t}-\mathrm{ZrO}_{2}$ phases. . . . . . . . . . . . . . . . .

2 (Color online) XANES of films with different Zr-B composition, offset upward with increasing $\mathrm{Zr}$ content. $\mathrm{Zr}$ foil and $\mathrm{ZrB}_{2}$ powder standards are labeled and indicated in red. Dashed curves are films deposited with no substrate heating; solid black curves are films deposited onto $600^{\circ} \mathrm{C}$ substrates. a) Normalized XAS at the $\mathrm{Zr}$ $\mathrm{K}$-edge of films as deposited. b) XAS of films after vacuum annealing at $1000^{\circ} \mathrm{C}$. First derivative spectra are inset. . . . . . . . . . . . . . . . . . . 17

3 (Color online) Magnitude of the Fourier transform of the EXAFS of films 1-4 (near $\mathrm{ZrB}_{2}$ stoichiometry). Dashed lines denote films deposited without substrate heating. Fitted curves appear in red with circular markers. Panels (a) and (b) show films as deposited, while panels (c) and (d) show them after annealing at $1000^{\circ} \mathrm{C}$. .

4 (Color online) Magnitude of the Fourier transform of the EXAFS of films 5 and 6 (B:Zr ratio 0.67). Dashed lines denote films deposited without substrate heating. Fitted curves appear in red with circular markers. a) As-deposited films. b) Films after vacuum annealing at $1000^{\circ} \mathrm{C}$. c) Component scattering paths and fit used for film 5 after annealing, offset for clarity. . . . . . . . . . . . . . . 


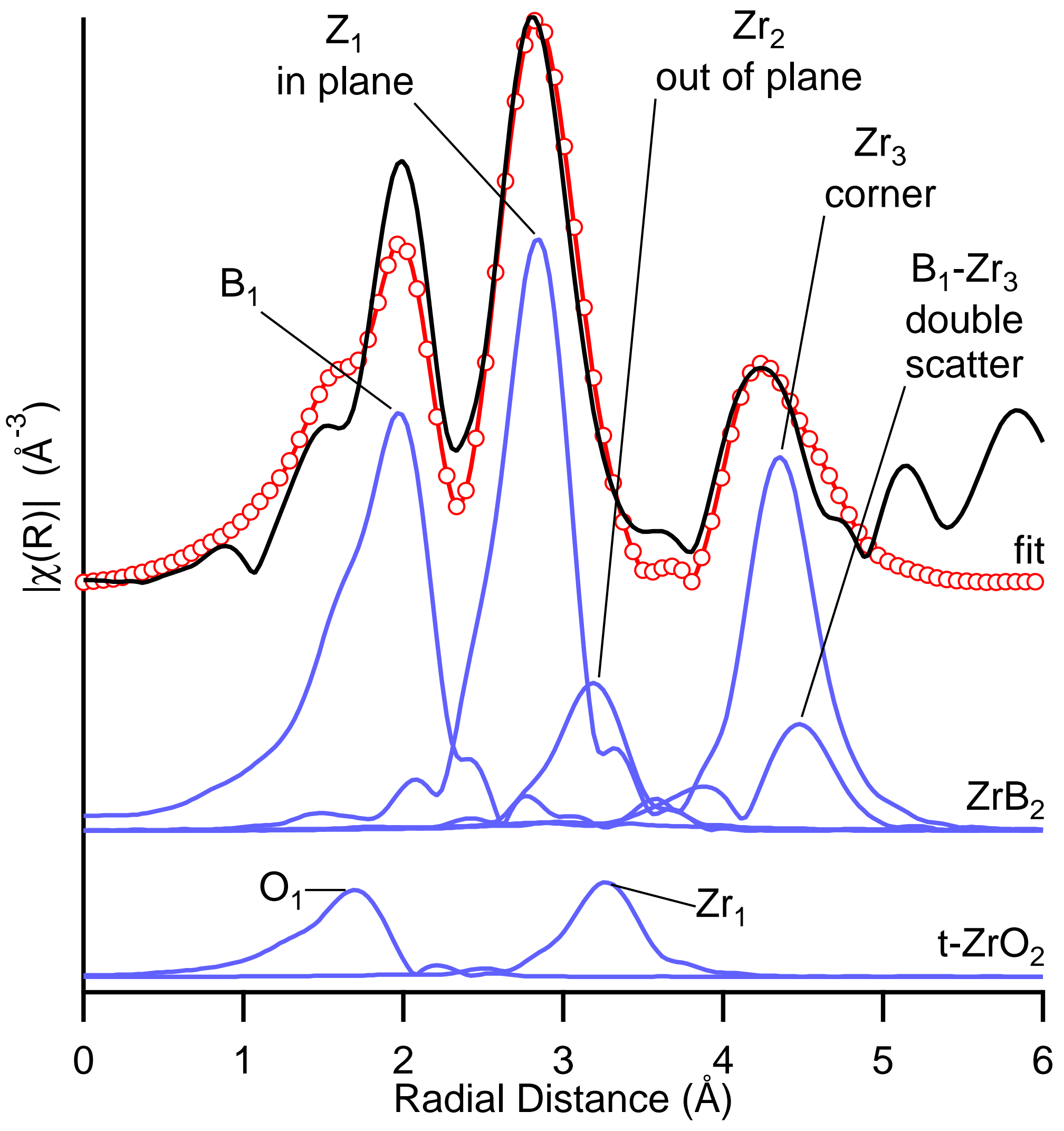




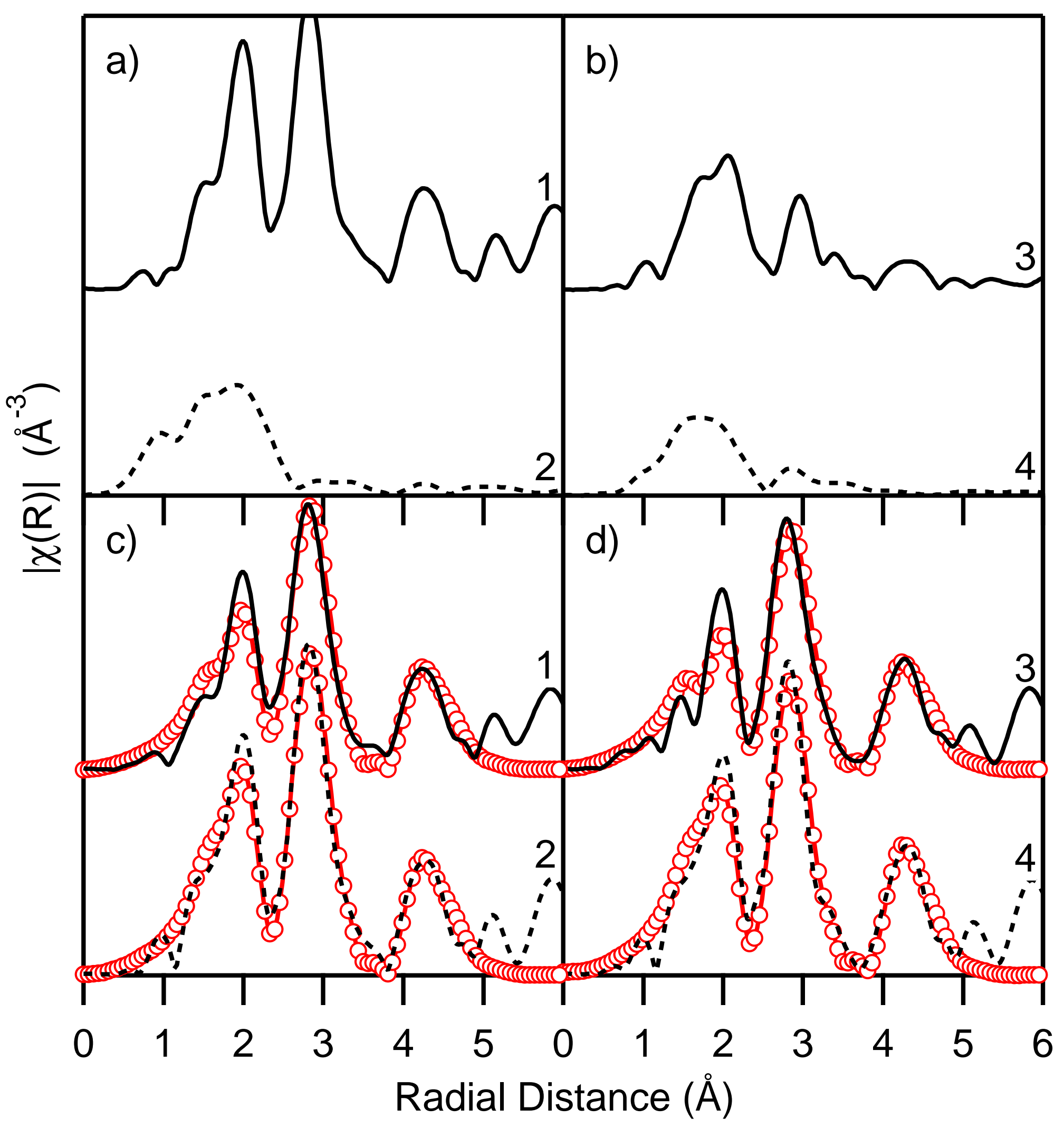




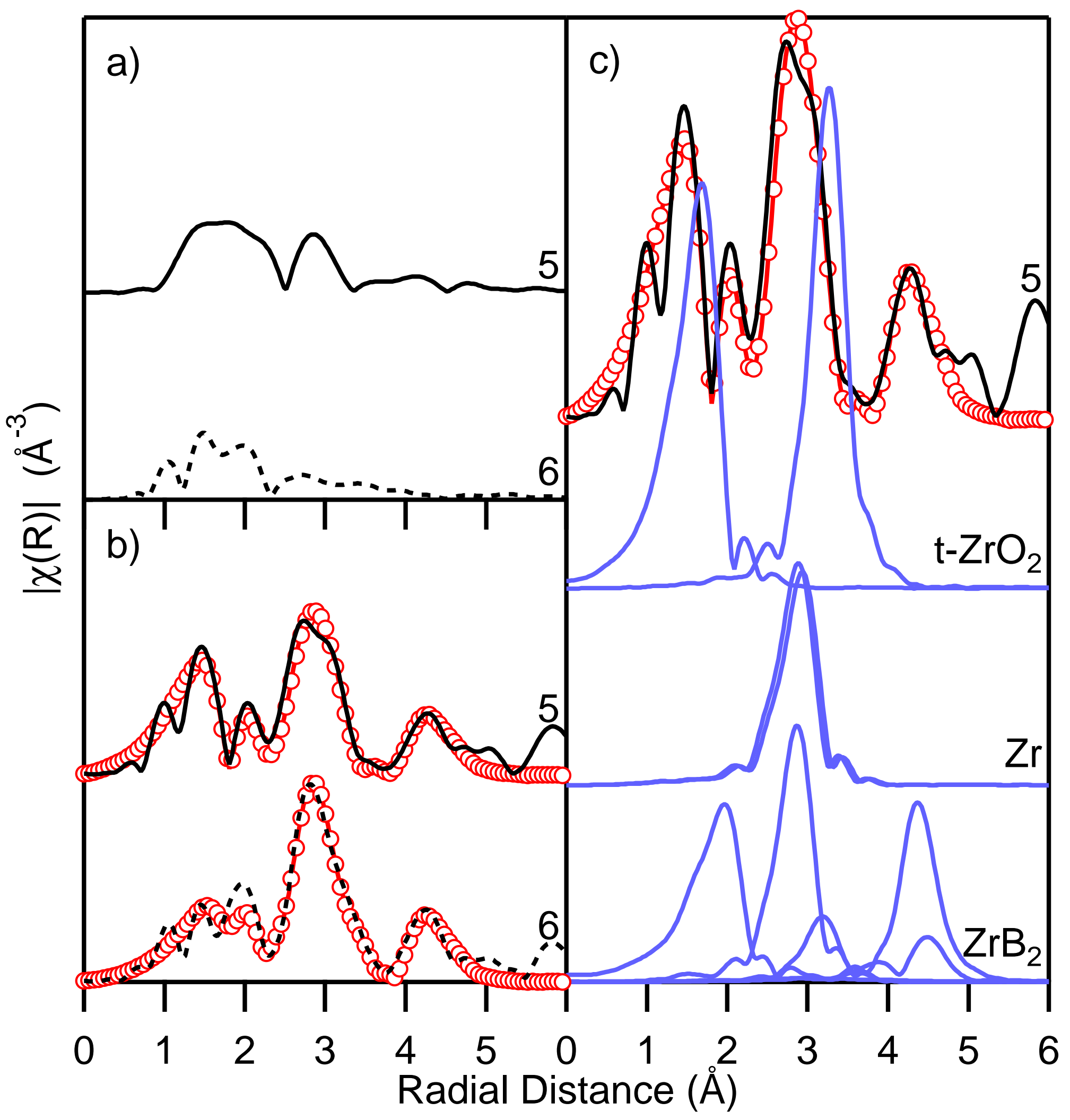

